\title{
LVII. Force-transformation, proper time, and fresnel's coefficient
}

\section{Prof. Frederick Slate}

To cite this article: Prof. Frederick Slate (1921) LVII. Force-transformation, proper time, and fresnel's coefficient, Philosophical Magazine Series 6, 41:244, 652-664, DOI: 10.1080/14786442108636254

To link to this article: http://dx.doi.org/10.1080/14786442108636254

册 Published online: 08 Apr 2009.

Submit your article to this journal

Џ Article views: 3

Q View related articles $\asymp$ 
LVII. Force-Transformation, Proper Time, and Fresnel's Coefficient. By Prof. Frederick Slate* *

GOR electronic conditions, Newtonian dynamics and relativity based on a Lorentz transformation are reducible to parallelism as mathematical schemes. The former introduces variable effective inertia where the latter treats inertia essentially as constant + . Moreover, relativity's method here can be assigned to widely inclusive grounds. Any attempt at a detailed physies by resolving further the data of energetics must countenance some flexible factoring of energy and of energy-flux in its tentative dynamics. Lagrange's equations are known to admit such alternatives: and no cogent reason exists for bounding the range of that proper freedom by their algebraic type $\ddagger$. As an implication of the present analysis, we achieve a hroader outlook, the gain of whose perspective is worth seeking.

Let an energy-transfer (W) of calculable amount be associated with a working speed $(v)$ at the close of an interval $(0, v)$, the frame being one among a "legitimate group." An interval like $(u, v)$ is covered by a difference. Then it is mathematically permissible to express (W) variously as a doubled kinetic energy (2E), and to prepare thus for corresponding mechanieal analogues. Accordingly, write a series of equivalents; not exhaustive, but meant to exemplify useful forms :

$$
\begin{aligned}
\mathrm{W} \equiv 2 \mathrm{E} \equiv\left(m_{1}\right)(z \boldsymbol{v})^{2}=\left(m_{1} z\right)\left(z v^{2}\right)=\left(m_{1} z^{2}\right)\left(v^{2}\right) \\
\\
\equiv\left(\mu^{\prime}\right)\left(c^{2}\right) \equiv\left(\mu \frac{v z}{c}\right)\left(c^{2}\right) . .
\end{aligned}
$$

The first parentheses in each factoring separate an assumed inertia-coefficient from a squared velocity; auxiliary velocities $(v \sqrt{z}, v z$, c, etc.) are then one inherent feature of any such series. The last two members employ a reduction to standard (or terminal) velocity $\S ;\left(m_{1}\right)$ is a constant;

* Communicated by the Author.

† Slate, Phil. Mag. vol. xxxix. p. 433; ; vol, xl. p. 31 ; vol. xli. p. 96. These papers are cited as (I.), (II.), (III.).

$\ddagger$ Generalized velocity and momentum are defined, and have been used practically, to realize this possibility. Incidentally, Abrabam's early success in extending Lagrange's equations to the electron may find partial explanation here (Theorie der Elektrizitat, vol. ii. p. 177 (1908)).

\$ Introduced at eq. (9) of (III.). Notice also eq. $(10,11,12)$ and the application in eq. $(20,21)$. 
$(z)$ must be in general a variable ratio. Whereas no particular factoring can modify the total energ?-flux $(d \mathrm{~W} / d t)$, certain coördinating conventions will reserve some latitude about details under each adoption of factors. A momentum (Q) involves inertia $(m)$, velocity $\left(v^{\prime}\right)$, and tangential forco (T), while (E) is invariant* :

$$
2 \mathrm{E} \equiv \mathrm{Q} v^{\prime} ; \quad \mathrm{Q} \equiv m v^{\prime} ; \mathrm{T} \equiv \frac{d}{d t}\left(m v^{\prime}\right) . \quad .
$$

Regarding (E) as a function of $\left(m, v^{\prime}\right)$; and defining

$$
v_{1} \equiv z v ; \quad Q_{1} \equiv m_{1} v_{1} ; \quad Q_{2} \equiv \mu^{\prime} c \equiv \mu v_{1} ; .
$$

the indispensable connexions among the group derived from equation (1) can be symbolized by

$$
\begin{aligned}
\frac{d \mathrm{~W}}{d t} \equiv 2 \frac{d \mathrm{E}}{d t}=2 v_{1}^{\prime} \mathrm{I}_{1}=c \mathrm{~T}_{2}= & 2\left(v^{\prime} \mathrm{T}-\frac{\partial \mathrm{E}}{\partial m} \frac{d m}{d t}\right) \\
& =v^{\prime} \mathrm{T}+\frac{\partial \mathrm{E}}{\partial v^{\prime}} \frac{d v^{\prime}}{d t} .
\end{aligned}
$$

The definite (constant) inertia $\left(m_{1}\right)$ is uniquely linked with $\left(\mathrm{T}_{1}\right)$, for which alone the partial $(\partial \mathrm{E} / \partial m)$ vanishes, and the principle of ris viva remains valid in the sense belonging to rigid dynamics. The force $\left(\mathrm{T}_{2}\right)$ is unique otherwise; its partner being $(c)$, the complementary partial $\left(\partial \mathrm{E} / \partial v^{\prime}\right)$ is suppressed. There is a second unpartitioned absorption of energy, also into kinetic form, but with an accompanying variable inertia $\left(\mu^{\prime}\right)$. This may be viewed as another sense of the vis viva principle. The recurrence of $\left(c^{2} d \mu^{\prime} \mid d t\right)$, with differing plausible values for $\left(\mu^{\prime}\right)$, has made itself noticeable throughout previous developments regarding electronic energy $f$.

The two abbreviated forms in equation (4), together with the two general members, yield the following relations among others :

$$
v^{\prime} \mathrm{T} \equiv v^{\prime}\left(m \frac{d v^{\prime}}{d t}+v^{\prime} \frac{d m}{d t}\right)=v_{1} \mathrm{~T}_{1}+\frac{1}{2} v^{\prime 2} \frac{d m}{d t}=c \mathrm{~T}_{2}-m v^{\prime} \frac{d v^{\prime}}{d t} .
$$

This amounts to establishing a transition between two activities (energy-fluxes), derived in turn from a variable inertia and from one that is constant. Either value of the

* Cf. (III.), p. 102 ; and eq. $(12,18)$.

+ See (III.) passim; it is plainly one goal of relativity's combinations. An important effort to construct a physical meaning for this expression is added by Sir J. J. Thomson, Phil. Mag. June 1920, p. 679. 
activity may be favoured by physical evidence; but on whichever one the preference thus falls, equation (5) or some simple equivalent shows how to calculate it in terms of the other, with due aid from a correcting partial derivative.

Presented in forms like

$$
\begin{aligned}
0=m_{1} v_{1}^{2}-\mu^{\prime} c^{2} & =\left(m_{1} v_{1}+i c \mu^{\prime}\right)\left(v_{1}+i c\right) \\
& =i\left(m_{1} v+i \mu v\right)\left(v_{1}+i c\right) \quad \text { [Real terms], }
\end{aligned}
$$

equation (1) sets in relief, first the idea of conservation (equal gain and loss at a transfer), and secondly the needful pairing of each alternative momentum with its own velocityfactor, when the complex product is expanded. All these aspects of the alove more comprehensive situation embrace ussentials of that correlation between Newtonian and "nonNewtonian" dynamics upon which this discussion turns. Beside the frequent appearance of $\left(\mu^{\prime}, \mu\right)$ just referred to, keeping the last members of equations $(1,5)$ somewhat at the front, mathematical prominence is assured to them through the Lagrange function and its derivative*. But this must not exclude the third member of equation (5). Not only was its type put forward earlier as a central necessity of general statement $t$, but it happens to offer also for the present phase rather direct contact with the systematic use of "proper time" and of "local time" i eculiar to relativity. "This distinction is largely superfluous for our Newtonian plan, since.without according it a place, the main dynamical relations resting upon it have been reproduced." That composite scheme of time-rariables must be truly secondary, if it be indeed carried into the fundamental equations through a coustincy of inertia made primary. Yet the newer doctrine takes so seriously what centres upon an entire parity of time and coördinate, that more adequate review of those points is in place, for which the activity $\left(v_{1} \mathrm{~T}_{1}\right)$ opens the way. A step or two in broader terms can be added, before limiting ourselves by the Lorentz electron's assumptions.

Define now

then

$$
m \equiv m_{1} z \equiv m^{\prime}, \quad v^{\prime} \equiv v \sqrt{z} ;
$$

$$
\mathrm{Q}^{\prime} \equiv m^{\prime} v \sqrt{\tau}=m_{1} v z^{3 / 2} \text {. }
$$

* The conception of kinetic potential has this consequence. Some special coincidences bave shown themselves aiready: (III.), p. 104; (II.), eq. (47).

+ In (I.), eq. (10); (II.); eq. (3). 
With these values, equation (5) gives

$$
\frac{v^{\prime} \mathrm{T}^{\prime}}{z}-v^{2} \frac{d n^{\prime}}{d t}=v \mathrm{I}_{1}-\frac{1}{2} v^{2} \frac{d m^{\prime}}{d t}=\frac{1}{z} \frac{d \mathrm{E}}{d t}-\frac{\mathrm{E}}{z^{2}} \frac{d z}{d t}=\frac{d}{d t}\left(\begin{array}{c}
\mathrm{E} \\
- \\
z
\end{array}\right) \text {. }
$$

From two factorings of $\left(Q_{1}\right)$, an important duplicule expression of $\mathrm{T}_{1}$ follows :

$$
\mathrm{T}_{1} \equiv \frac{d}{d t}\left(m_{1} z v\right)=m_{1} \frac{d v_{1}}{d t}=m^{\prime} \frac{d v}{d t}+v \frac{d m^{\prime}}{d t} . \quad .
$$

Since an activity of importance for the electron grows out of $\left(v \mathrm{~T}_{1}\right)$, which equation (7) connects with an entrgytransfer $(\mathrm{W} / z)$, the latter quantity will presently daim attention. Next defne $m \equiv m_{1} z^{2} \equiv m^{\prime \prime}$; with $v^{\prime} \equiv v$, and $Q^{\prime \prime} \equiv m^{\prime \prime} v$. These lead at once to

$$
2 v_{1} \mathrm{~T}_{1}-v \mathrm{~T}^{\prime \prime}-m_{1} z^{2} v \frac{d v}{d t}=0=z_{1}\left[2 v_{1}^{\prime} \mathrm{T}_{1}-v^{r} \mathrm{I}^{\prime \prime}-m_{1} z^{2} v^{\frac{d v}{d t}}\right] \text {, }
$$

the factor $\left(z_{1}\right)$ being arbitrary. Finally it is evident that

$$
2 z\left[v \mathrm{~T}_{1}-e^{2} \frac{d m^{\prime}}{d \iota}\right]=c^{2}\left[\frac{d \mu^{\prime}}{d t}-\frac{d m^{\prime \prime}}{d t}\right] . . .
$$

The supposition is continued, that c.G.s. units of length and time (fluxion time) fix values for all observed velocities; either $\left(v_{0}\right)$ in the standard frame (F), or $\left(c_{0}^{\prime}\right)$ in any frame (U). Therefore $\left(d t=d t_{o}{ }^{\prime}\right)$ in the defining ratios

$$
v_{o} \equiv \frac{d x_{o}}{d t_{o}} ; \quad v_{o}^{\prime} \equiv \frac{d x_{o}^{\prime}}{d t_{o}{ }^{\prime}} ; \quad . \quad . \quad . \quad .
$$

the accents add only a helpful indication of the "observingframe." This will not bar auxiliary time-differentials, lor convenient expression of auxiliary velocities, originally determined by c.G.s. units. Thus, if in relation to (F,U)

$$
\left.\begin{array}{l}
d \tau \equiv \frac{d t_{0}}{z} ; \quad \frac{d x_{o}}{d \tau}=v_{1}, \frac{d}{d \tau}\left(\frac{d x_{o}}{d \tau}\right)=\frac{d \eta_{1}}{d \tau}=z^{\frac{d v_{1}}{d t_{0}} ;} \\
d \tau^{\prime} \equiv \frac{d t_{o}^{\prime}}{z^{\prime}} ; \frac{d x_{o}^{\prime}}{d \tau^{\prime}}=z^{\prime} v_{o}^{\prime} \equiv v_{1}^{\prime}, \frac{d}{d \tau^{\prime}}\left(\frac{d x_{o}{ }^{\prime}}{d \tau^{\prime}}\right)=\frac{d v_{1}{ }^{\prime}}{d \tau^{\prime}}=z^{\prime} \frac{d r_{1}{ }^{\prime}}{d t_{o}{ }^{\prime}}
\end{array}\right\}
$$

Consequently, multiples of previous forces and activities may be drawn upon for the algebra, from parallel series like

$$
\begin{aligned}
& m_{1} \frac{d^{2} x_{o}}{d \tau^{2}}=\approx \mathrm{T}_{1}, \quad \frac{d r_{o}}{d \tau}\left(m_{1} \frac{d^{2} x_{o}}{d \tau^{2}}\right)=\approx \frac{d}{d t_{o}}\left(\begin{array}{c}
m_{1} v_{1}{ }^{2} \\
2
\end{array}\right)=z \frac{d \mathrm{E}}{d t_{o}}=\frac{d \mathrm{E}}{d \tau} ;
\end{aligned}
$$

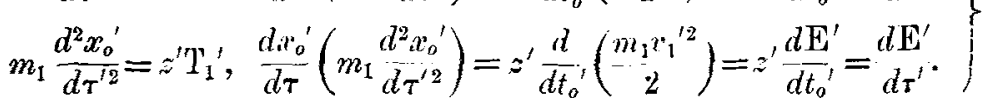


The special auxiliaries $\left(v_{c}{ }^{\prime}, v_{c}\right)$, which in our rendering replace the Einstein velocities, can be brought formally closer to the latter under a similarly expanded notation. Instead of accepting them initially as "distorted" (but C.G.S.) velocities *, throw each of their defining ratios into terms of its own "distorted" length and time :

$$
v_{c}^{\prime} \equiv \frac{v_{o}-u}{1-\frac{u v_{o}}{c^{2}}} \equiv \frac{d x^{\prime}}{d t_{c}^{\prime}} ; \quad v_{c} \equiv \frac{v_{o}^{\prime}+u}{1+\frac{u v_{o}}{c^{2}}} \equiv \frac{d x_{c}}{d t_{c}} ;
$$

then

$$
\frac{d x_{c}}{d t_{o}^{\prime}}=\gamma(u)\left(v_{o}^{\prime}+u\right) ; \quad \frac{d x_{c}^{\prime}}{d t_{o}}=\gamma(u)\left(v_{o}-u\right) .
$$

In effect, details are here borrowed from relativity; but again another conception of them is attached to the notation :

$$
\begin{array}{ll}
x_{c}{ }^{\prime} \equiv \gamma(u)\left(x_{o}-u t_{o}\right) ; & t^{\prime} \equiv \gamma(u)\left(t_{o}-\frac{u}{c^{2}} x_{o}\right) ; \\
x_{c} \equiv \gamma(u)\left(x_{o}{ }^{\prime}+u t_{o}{ }^{\prime}\right) ; & t_{c} \equiv \gamma(u)\left(t_{o}^{\prime}+\frac{u}{c^{2}} x_{o}^{\prime}\right) .
\end{array}
$$

Let now the more general $\left(z, z^{\prime}\right)$ be particularized provisionally as $\left(\gamma\left(v_{o}\right), \gamma\left(v_{o}^{\prime}\right)\right)$. It is directly provable that

$$
\begin{aligned}
d \tau \equiv \frac{d t_{o}}{\gamma\left(v_{o}\right)}=\frac{d t_{c}{ }^{\prime}}{\gamma\left(v_{c}{ }^{\prime}\right)} ; & d \tau^{\prime} \equiv \frac{d t_{o}^{\prime}}{\gamma\left(v_{o}{ }^{\prime}\right)}=\frac{d t_{c}}{\gamma\left(v_{c}\right)} ; \\
d \tau & =d \tau^{\prime} \quad\left[v_{0}=v_{o}^{\prime}\right] ;
\end{aligned}
$$

which is our version of "proper-time invariance" for frames $(U)$. At this point, as at others, a group of four quatitities doubles relativity's pair, and a pair $\left(d \tau, d \tau^{\prime}\right)$ distinguishes where relativity does not. Both duplications are referable to combining the two aspects of "simultaneous": it is evident that, whenever observed $\left(v_{o}^{\prime}, v_{0}\right)$ coincide with specified series $\left(\vartheta_{c}^{\prime}, v_{c}\right)$, the values calculated for the other frame will coincide also with the $\left(v_{o}, v_{o}^{\prime}\right)$ corresponding to such $\left(v_{c}{ }^{\prime}, v_{c}\right)$.

Differentiate equations (14), noting equations (16) and previously demonstrated equalities + ; which gives

$$
\left.\begin{array}{l}
\gamma^{2}\left(v_{o}\right) \frac{d v_{o}}{d \tau}=\gamma^{3}\left(v_{o}\right) \frac{d v_{o}}{d t_{o}}=\gamma^{2}\left(v_{c}{ }^{\prime}\right) \frac{d v_{c}{ }^{\prime}}{d \tau}=\gamma^{3}\left(v_{c}{ }^{\prime}\right) \frac{d v_{c}{ }^{\prime}}{d t_{c}{ }^{\prime}}=\frac{\mathrm{T}_{o}}{m_{0}} ; \\
\gamma^{2}\left(v_{o}{ }^{\prime}\right) \frac{d v_{o}{ }^{\prime}}{d \tau^{\prime}}=\gamma^{3}\left(v_{o}^{\prime}\right) \frac{d v_{o}{ }^{\prime}}{d t_{o}^{\prime}}=\gamma^{2}\left(v_{c}\right) \frac{d v_{c}}{d \tau^{\prime}}=\gamma^{3}\left(v_{c}\right) \frac{d v_{c}}{d t_{c}}=\frac{\mathrm{T}_{o}{ }^{\prime}}{m_{0} \gamma(u)}
\end{array}\right\}
$$

* See (I.), pp. 436,438 ; (II. ), pp. 40, 41.

+ In (II.), eq. $(19,25)$. Consider eq. $(21,24)$ there and eq. (17) here for features of likeness and difference. A "reduction-factor" and a " distorted time" are equivalent in operation. 
The results are patterned after a "force-invariance for frames (U)." It is relevant to completed comparison, that Newtonian dynamics and relativity control these similar resonrces. Nevertheless, no such steps of algebraic manipulation, subject mainly to notational consistency, can acquire physical standing in either plan, except by the one test.

Under the supposition $z \equiv \gamma\left(v_{o}\right)$, we approach the assumptions for the Lorentz electron and the frame (F); but retain as before a constant inertia $\left(m_{1}\right)$, whose ratio to the standard $\left(m_{0}\right)$ can be assigned later. Resume from previous notation and values :

$$
\mathrm{T}_{1}=m_{1} \gamma^{3}\left(v_{o}\right) \frac{d v_{o}}{d t_{o}} ; \mathrm{T}_{o} \equiv{\frac{m}{m_{1}}}_{1} \mathrm{~T}_{1} ; m^{\prime} \equiv m_{1} \gamma\left(v_{o}\right) ; v \mathrm{~T}_{1}=c^{2} \frac{d m^{\prime}}{d t_{o}} *
$$

Add, from equations $(12,9)$ :

$$
v_{1} \mathrm{~T}_{1}=\frac{d \mathrm{E}}{d \overline{t_{o}}} \doteq c^{2} \frac{d m^{\prime}}{d \tau} ; \quad \frac{1}{\gamma\left(v_{0}\right)} \frac{d \mathrm{E}}{d t_{0}}=\frac{1}{\gamma^{2}\left(v_{o}\right)} \frac{d \mathrm{E}}{d \tau} ; \quad c^{2} \frac{d \mu^{\prime}}{d t_{0}}-c^{2} \frac{d m^{\prime \prime}}{d t_{o}}=0 .
$$

Whatever condition reduces to zero the first parenthesis in equation (10) makes the difference $\left(m^{\prime \prime}-\mu^{\prime}\right)$ constant. This requires

$$
m_{1} z^{2}=\left(m_{1} z^{2}\right) \frac{v_{o}^{2}}{c^{2}}+c_{1} ; \quad c_{1}=m_{1} z^{2}\left(1-\frac{v_{o}^{2}}{c^{2}}\right)=m_{1}
$$

Further,

$$
\left[z^{2} \equiv \gamma^{2}\left(v_{o}\right)\right] \text {. }
$$

$$
\begin{array}{r}
\mu^{\prime}=m_{1}\left(\gamma^{2}\left(v_{o}\right)-1\right)=\frac{m_{1} v_{o}^{2}}{c^{2}-v_{o}^{2}} ; \mu \equiv \mu^{\prime} \frac{c}{v_{1}}=\frac{m_{1} v_{o}}{\sqrt{c^{2}-v_{o}^{2}}} ; \\
\mu c=m_{1} \gamma\left(v_{o}\right) v_{o} .
\end{array}
$$

The "transverse mass" and the momentum of relativity's Lorentz electron emerge thus simply from general expressions through an assumption regarding activity. Remark that $\left(1-v_{0}^{2} / c^{2}\right)$ is an intrinsic factor in the resistance problem, and in equation (20); its equality with $\left(1 / z^{2}\right)$ is introduced by a condition open to revision.

To class " multiple forces," like $\left(z \mathrm{~T}_{1}, z^{\prime} \mathrm{T}_{1}{ }^{\prime}\right)$ in equations (13), as being of "Minkowski" type suggests bringing the original $\left(\mathrm{T}_{1}, \mathrm{~T}_{1}^{\prime}\right)$ under a "Newton" type ; indeed the latter are part of normal Newtonian dynamics. The work and the impulse of the two force-classes offer several points

* The general bearing of the "resistance problem" and its terminal velocity is to be kept in mind: (II.), p. 35 ; (III.) passim, but especially eq. $(6,22)$. Distinguish two uses of the symbol $\left(v_{1}\right)$. 
to work out. Consider first in $(F)$ the force $\left(K_{1}\right)$ and its activity $\left(\mathrm{A}_{1}\right)$ :

$$
\begin{aligned}
\mathrm{K}_{1} \equiv m_{1} \frac{d^{2} x_{0}}{d \tau^{2}}=\gamma\left(v_{0}\right) \mathrm{T}_{1} ; \quad \mathrm{A}_{1} \equiv \frac{d x_{o}}{d \tau} \mathrm{K}_{1} & =\gamma\left(v_{0}\right) v_{1} \mathrm{~T}_{1} \\
& =\gamma^{2}\left(v_{0}\right) c^{2} \frac{d m^{\prime}}{d t_{o}}
\end{aligned}
$$

Keeping equations $(1,4)$ in view, determine the work $\left(W_{1}\right)$ for an interval $\left(u, v_{*}\right)$ :

$$
\begin{aligned}
W_{1} \equiv 2 \int_{u}^{v_{o}} K_{1} \frac{d x_{o}}{d t} d r & =m_{1} c^{2}\left(\frac{c^{2}}{c^{2}-v_{o}^{2}}-\frac{c^{2}}{c^{2}-u^{2}}\right) \\
& =m_{1} c^{2}\left(\frac{v_{o}^{\prime}}{c^{2}-v_{o}^{2}}-\frac{u^{2}}{c^{2}-u^{2}}\right) \\
& =c^{2}\left(\mu^{\prime}-\mu_{0}^{\prime}\right)=W-W_{0}\left[z \equiv \gamma\left(v_{o}\right)\right] .
\end{aligned}
$$

"Therefore

$$
m_{1} c^{2} c_{c^{2}-v_{o}^{2}}^{v^{2}}-m_{a} c^{2} \frac{c^{2}}{c^{2}-v_{o}^{2}}=m_{1} c^{2} \frac{u^{2}-v^{2}}{c^{2}-u^{2}}=-m_{1} c^{2} ;
$$

which might be rated a trivial identity, did not our purpose connect it profitably with equations $(6,18)$. Denote by $\left(R^{\prime}\right)$ the product of the real terms in equation (6), by $\left(\mathrm{R}^{\prime \prime}\right)$ the product of the imaginary terms, and by $\left(\mathbf{R}_{1}\right)$ their sum Then for present values $\left(R^{\prime}+R^{\prime \prime}\right)$ is seen to $r$ peat the first member of equation (24). Hence $d \mathrm{R}_{1} / d t_{o}=0$, and referring to equation (7) also,

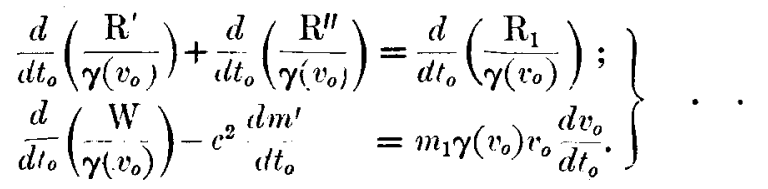

Without elaborating every detail, this outline goes far enough to be convincing : it retraces essentially the "step up" and step down" with the factor $\left(\gamma\left(v_{0}\right)\right)$ which reaches Newtonian activity in relativity's procedure-attainable brevity or directness is not for the moment an issue. The repetition with quantities belonging to a frame (U) is so nearly routine that it is omitted. On any line of analysis, the decision lies in the resistance problem, whether at transfer a reduction factor shall be applied to values first written for $(F)$ or for $(U)$. The turning-point is located in

* Moreover, this "invariant function" is plainly an offshoot from the fundamentals of the resistance problem. 
the answer to the question: Which relative speed $(v)$ is phrsically responsible for the resistance $\left(m_{1} k v^{2}\right)$ ?

The manifold bearings of the force $\left(\mathrm{T}_{1}\right)$ justify adding a word about its impulse; and transitions between frames (F, U) where it occurs. As in equation (23), take the interval $\left(u, v_{o}\right)$ in $(\mathrm{F})$, important in corresponding to the interval $\left(0, v_{0}-u\right)$ or $\left(0, v_{c}{ }^{\prime}\right)$ in (U). Adjust a velocity $\left(v_{u}\right)$ in (U) to meet the condition making momentum-changes permanently equal; as $\left(v_{c}^{\prime}\right)$ affected an energy-change :

$$
m_{1} v_{u} \equiv m_{1}\left(\gamma\left(v_{o}\right) v_{o}-\gamma(u) u\right) . \text {. . . . }
$$

Then the equal time-rates entail

$$
m_{1} \frac{d v_{u}}{d t_{o}}=m_{1} \frac{d}{d t_{o}}\left(\gamma\left(\boldsymbol{v}_{o}\right) v_{o}\right)=m_{1} \frac{d v_{1}}{d t_{o}}=\mathrm{T}_{1} ; .
$$

the tangential accelerations and their forces thus measured in $(\mathrm{F}, \mathrm{U})$ are equal ; and the activities as well,

Consequently,

$$
v_{u}^{\prime} \mathrm{T}_{1}=\mathrm{T}_{1}\left(\gamma\left(r_{o}\right) r_{o}-\gamma(u) u\right) . \quad . \quad . \quad \text {. }
$$

$$
\left.\begin{array}{l}
\mathrm{T}_{1}\left(v_{1}-v_{u}\right)=\mathrm{T}_{1} \gamma\left(u_{,}^{\prime} u=\gamma(u) \mathrm{T}_{1}\left[v_{o}-\left(r_{o}-u\right)\right] ;\right. \\
\mathrm{T}_{1} v_{u}-\mathrm{T}_{1} \gamma(u)\left(v_{o}-u\right)=\mathrm{T}_{1} r_{o}\left(\gamma\left(v_{o}\right)-\gamma(u)\right) .
\end{array}\right\}
$$

Understanding that $\left(m_{0}\right)$ in $\left(\mathrm{T}^{\prime}{ }^{\prime}\right)$ is replaced by $\left(m_{1}\right)$ for this occasion, the work-relation appears * :

$$
\begin{array}{r}
\int_{0}^{u} \mathrm{I}_{1} v_{u} d t_{o}-\gamma(u) \int_{0}^{v_{c}^{\prime}} \mathrm{T}_{c}^{\prime}{ }^{\prime} \dot{k}_{c}^{\prime} d t_{o}=\int_{u}^{v_{o}} \mathrm{~T}_{1} v_{o}\left(\gamma\left(v_{o}\right)-\gamma(u)\right) d t_{o} \\
=\frac{c^{2}}{2} \int_{u}^{v_{o}} \frac{d \mu^{\prime}}{d t_{o}} d t_{o}-c^{2} \gamma(u) \int_{u}^{v_{o}} \frac{d n^{\prime}}{d t_{o}} d t_{o} .
\end{array}
$$

This result does something to enlarge command of interdependence between (F, U). But its better service, perhaps, is to enforce again two dynamical ideas that pervade these investigations : first, that the attacks through energy and through momentum, though reconcilable, are not entirely congruent; and secondly, that the treatment of rariable inertia breaks away from what suffices for constant inertia. Each term in the first member builds upon its own equal acceleration $\left(d v_{1} / d t_{o}, d v_{o} / d t_{o}\right)$ in $(\mathrm{F}, \mathrm{U})$. 'This is not on the surface true of the second member, since $\left(\mathrm{T}_{1} v_{1}\right)$ belongs to the third member of equation (8), and $\left(\mathrm{T}_{1} v_{0}\right)$ to its fourth member $t$. The above expansion repeats for an observation-

* Relying on (I.), pp. 436, 438; or on (II.), p. 44.

+ Cf. the earlier comment; (II.), pp. 38, 39 . 
frame (U) ; with its distinctive notation, and introducing for $(\mathrm{F})$ a companion to $\left(v_{c}\right)$ similar to $\left(v_{u}\right)$ in (U).

Some mention has been made already of a "Fresnel coefficient" $(\kappa)$, and of a meaning for it as "inertia-drag," when associated with the frame (F). There proves to be, however, a pair of such coefficients $\left(\kappa, \kappa^{\prime}\right)$, symmetrically related to $(\mathrm{F}, \mathrm{U})$, like $\left(d \tau, d \tau^{\prime}\right)$ of equations $(12)$. Something remains to say about this pair, connected with our Newtonian forces $\left(\mathrm{T}_{o}, \mathrm{~T}_{a}, \mathrm{~T}_{o}^{\prime}, \mathrm{T}_{a}^{\prime}\right)$, including now under those symbols values for either the more general $\left(m_{1}\right)$ or the more particular $\left(m_{0}\right)$, as the context may indicate. We can quote for observation-frame $(\mathrm{F})^{*}$ :

$$
\left.\begin{array}{l}
\kappa \equiv \frac{v_{o}-v_{c}{ }^{\prime}}{u}=\frac{c^{2}-v_{o}^{2}}{c^{2}-u v_{o}}=\frac{c^{2}-v_{c}{ }^{\prime 2}}{c^{2}+u c_{c}^{\prime}}=1-\frac{v_{o} v_{c}^{\prime}}{c^{2}} ; \\
\kappa \mathrm{T}_{a}^{\prime}=m_{1} \gamma\left(v_{o}\right) \frac{d v_{o}}{d t_{o}} ; \kappa \mathrm{T}_{o}=m_{1} \gamma(u) \gamma\left(v_{c}^{\prime}\right) \frac{d v_{c}^{\prime}}{d t_{c}} \cdot
\end{array}\right\}
$$

Basing frankly on symmetry for the defining ratio (but succeeding members are demonstrable), write then for an observation-frame $(\mathrm{U})$, noting $\left(u^{\prime}=-u\right)$ :

$$
\kappa^{\prime} \equiv \frac{v_{o}{ }^{\prime}-v_{c}}{u^{\prime}}=\frac{v_{c}-v_{o}{ }^{\prime}}{u}=\frac{a^{2}-v_{o}^{\prime 2}}{c^{2}+u v_{o}{ }^{\prime}}=\frac{c^{2}-v_{c}{ }^{2}}{c^{2}-u v_{c}}=1-\frac{v_{o}{ }^{\prime} r_{c}}{c^{2}}
$$

In the special view of relativity, $\left(\kappa, \kappa^{\prime}\right)$ become equal. $\mathrm{Or}$ here visibly through the coincidences that are mentioned below equations (16). But our Newtonian scheme, in the several instances enumerated, gives enlarged reciprocity to frames $(\mathrm{F}, \mathrm{U})$; independent phenomena originating (we may say) in either are convertible into terms of the other. The contrast with treating the same phenomena indifferently in all frames of the group is certainly not to Newton's disadvantage.

Under the definition of $\left(\kappa^{\prime}\right)$, the proofs are direct that

$$
\left.\begin{array}{rl}
\kappa^{\prime}\left(\frac{\mathrm{T}_{o}{ }^{\prime}}{\gamma(u)}\right) & =m_{1} \gamma(u) \gamma\left(v_{c}\right) \frac{d v_{c}}{d t_{o}} ; \kappa^{\prime}\left(\frac{\mathrm{T}_{a}}{\gamma(u)}\right)=m_{1} \gamma\left(v_{o}^{\prime}\right) \frac{d v_{o}^{\prime}}{d t_{o}^{\prime}} ; \\
\frac{\mathrm{T}_{a}}{\gamma(u)} & =m_{1} \gamma\left(v_{o}{ }^{\prime}\right) \frac{d v_{o}^{\prime}}{d t_{o}^{\prime}}+\left(v_{o}^{\prime}+u\right) \frac{d}{d t_{o}^{\prime}}\left(m_{1} \gamma\left(v_{o}^{\prime}\right)\right) .
\end{array}\right\}
$$

These round out the symmetry because, allowing always

* From (II.), pp. 38, 43. Eq. $(5,13,24,26)$ there define $\left(\mathrm{T}_{o}, \mathrm{~T}_{a}\right.$, $\mathrm{To}^{\prime}, \mathrm{T}_{a}{ }^{\prime}$ ). 
for the weighting factor $(\gamma(u))$, and remembering $\left(d t_{o}=d t_{o}^{\prime}\right)$, the last equality stands in exact parallel with

$$
\mathrm{T}_{a}^{\prime} \equiv m_{1} \gamma\left(v_{o}\right) \frac{d v_{o}}{d t_{o}}+\left(v_{o}-u\right) \frac{d}{d t_{o}}\left(m_{1} \gamma\left(v_{o}\right)\right)^{*} .
$$

Next use $\left(\kappa, \kappa^{\prime}\right)$ with those multiples $\left(\mathrm{K}_{\mathrm{F}}, \mathrm{K}_{\mathrm{F}}{ }^{\prime}, \mathrm{K}_{u}{ }^{\prime}, \mathrm{K}_{u}\right)$ of $\left(\mathrm{T}_{0}, \mathrm{~T}_{a}, \mathrm{~T}_{o}{ }^{\prime}, \mathrm{T}_{a}^{\prime}\right)$ which have been subjected to a "Minkowski transformation "; they are all of the same type as $\left(\mathrm{T}_{o}\right)$ itself $\dagger$. The combinations disclose another phase of symmetry :

$$
\left.\begin{array}{l}
\kappa \mathrm{K}_{\mathrm{F}}=\gamma(u) m_{1} \gamma\left(v_{c}{ }^{\prime}\right) \frac{d v_{c}{ }^{\prime}}{d t_{o}} ; \quad \kappa^{\prime} \mathrm{K}_{\mathrm{F}}^{\prime}=\gamma(u) m_{1} \gamma\left(v_{o}^{\prime}\right) \frac{d v_{o}^{\prime}}{d t_{o}{ }^{\prime}} ; \\
\kappa \mathrm{K}_{u}^{\prime}=\gamma(u) \prime^{\prime \prime} \gamma\left(v_{c}\right) \frac{d v_{c}}{d t_{o}} ; \quad \kappa \mathrm{K}_{u}=\gamma(u) m_{1} \gamma\left(v_{o}\right) \frac{d v_{o}}{d t_{o}}
\end{array}\right\}
$$

Since $\gamma(u)=\gamma\left(u^{\prime}\right)$, the common factor $\gamma(u)$ signalizes again the fully reciprocal relations of $(F, U)$ to transfer back and torth. The effect otherwise of $\left(\kappa, \kappa^{\prime}\right)$ is to cancel from each force's companion the term depending on variable inertia $\ddagger$. Put together equations $(17,33,34)$, bringing out once more the vital divergence from relativity through employing a time-variable uniformly in all frames. Whatever the influence in other directions of such comparisons, they will not prejudice judgment to undervalue the mental vision which detected this fitness of local (or distorted) time to restore an invariance in magnitude, as well as preserve a mathematical type.

By drawing upon the sequence of equations (17), the original equation (9) can be employed to recalculate for transfers anong frames (U). That repetition passed over as nearly self-evident, new conclusions remain to extraci from the comment attached to equation (5), that coördinates one activity $\left(v_{1} T_{1}\right)$ with an adjustable set of activities $\left(v^{\prime} \mathrm{T}\right)$. To grasp its full scope, and to weigh habitually all its alternatives, may tend to clear perplexing or obscure questions, when the energy is assigned in advance, to which that equation shall be accommodated. Exhaustive inquiry

* Laid down by way of fundamental premise in (II.), eq. (12).

+ See (II.), p. 43. They will not be confused with "Minkowski forces," like $\left(z \mathrm{~T}_{3}, z^{\prime} \mathrm{T}_{1}^{\prime}\right)$ in eq. (13) above.

I Returning closely to the assumption of (II.), p. 37. This point gains in importance, when the intimate bearing of Fresnel's coefficient upon the physical action is conceded.

Phil. Mag. S. 6. Vol. 41. No. 244. April 1921. 2 X 
into the combination

$$
v^{\prime} \mathrm{T}=(z v) \mathrm{T}_{1}+\frac{1}{2} v^{\prime 2} \frac{d m}{d t} \quad . \quad . \quad . \quad .
$$

should be generally fruitful, under suggestion from the successful analysis for Abraham's electron *. Bringing in electromagnetic activity $\left(d \mathrm{M} / d t_{o}\right)$ at the value which mainly controls the reasoning here,

$$
\frac{d \mathrm{M}}{d t_{o}}=v_{o}\left[\mathrm{~T}_{1}+\frac{m^{\prime}}{4} \frac{d v_{o}}{d t_{o}}\right], \ldots . .
$$

its divergence from $\left(v_{0} \mathrm{~T}_{1}\right)$ is not such a discrepancy logically, as leaning on $\left(v_{1} \mathrm{~T}_{1}\right)$ exclusively would imply. Nor is its removal at once compulsory, by inventing some release of the electron's internal energy, for example. But concession must be made to two possibilities: first that $(z)$ is not exactly equal to $\left(\gamma\left(v_{o}\right)\right)$; and, secondly, that the total energy-flux is greater than $\left(v_{1} \mathrm{~T}_{1}\right)$, on account of imperfect conversion into electromagnetic form. We can illustrate both points by returning to equation (9), put into these terms :

$$
\begin{aligned}
v_{o}\left(\frac{\mathrm{T}^{\prime \prime}}{\gamma\left(v_{o}\right)}\right)=2 v_{o}^{\prime} \mathrm{T}_{1}-m^{\prime} v_{o} \frac{d v_{o}}{d t_{o}} & =v_{o} \mathrm{~T}_{1}+v_{o}{ }^{2} \frac{d m^{\prime}}{d t_{o}} \\
& =v_{o} \mathrm{~T}_{1}\left(1+\frac{v_{o}{ }^{2}}{c^{2}}\right) .
\end{aligned}
$$

If $\left(m_{1}\right)$ and the last parenthesis be associated, the larger energy-flux denoted by the first nember would appear as due to a graded increase of effective inertia. The idea read into Fresnel's coefficient is revived. Proceed next to revised magnitudes of $\left(\mu^{\prime}, \mu\right)$, determined by an imperfect conversion that leaves $\left(m_{1} r_{0}^{2} / 2\right)$ of (literal) kinetic energy :

$$
\begin{aligned}
\mu_{1}^{\prime} c^{2} & \equiv m_{1} v_{1}^{2}-\frac{m_{1} v_{o}{ }^{2}}{2} ; \mu_{1}^{\prime}=\frac{\mu^{\prime}}{2}\left(1+\frac{v_{0}^{2}}{c^{2}}\right)=\frac{v_{o}^{2}}{c^{2}}\left(\frac{m^{\prime \prime}+\mu^{\prime}}{2}\right) ; \\
\mu_{1} & \equiv \frac{c}{v_{1}} \mu_{1}^{\prime}=\frac{\mu}{2}\left(1+\frac{v_{o}^{2}}{c^{2}}\right) .
\end{aligned}
$$

Hence

$$
2 \gamma\left(v_{o}\right) \mu_{1}^{\prime} \frac{c^{2}}{v_{o}^{2}} \frac{d v_{o}}{d t_{o}}=\mathrm{T}_{1}\left(1+\frac{v_{o}^{2}}{c^{2}}\right)=\frac{\mathrm{T}^{\prime \prime}}{\gamma\left(v_{o}\right)} ; .
$$

and the set $\left(\mathrm{T}^{\prime \prime}, \mu_{1}^{\prime}, \mu_{1}\right)$ grow out of $\left(\mathrm{T}_{1}, \mu^{\prime}, \mu\right)$ by introducing the same essential factor, which equations (38) make

* In (III.), eq. (19) to (24). We are continuing the substitution of $\left(m_{1}\right)$ for $\left(m_{0}\right)$. 
characteristic of that imperfect conversion. This becomes significant for comparison with previous results *. Continuing along the same line, we find for the assumed time-rate of electromagnetic energy,

$$
\begin{aligned}
v_{o}\left(\mathrm{~T}_{1}+\frac{m^{\prime}}{4} \frac{d v_{o}}{d t_{o}}\right) & =\left(\frac{\mathrm{T}^{\prime \prime}}{2 \gamma\left(v_{o}\right)}+\frac{3}{4} m^{\prime} \frac{d v_{o}}{d t_{o}}\right) v_{o} \\
& =\left[\gamma\left(v_{o}\right) \mu_{1}^{\prime} \frac{c^{2}}{v_{o}{ }^{2}}+\frac{3}{4} m^{\prime}\right] v_{o} \frac{d v_{o}}{d t_{o}}, .
\end{aligned}
$$

where the brackets again set off an effective inertia. The facts can be summarized into saying that a composite operator (scale-factor) must be applied; each element in it to the proper quota of $\left(m_{1}\right)$. Equation (9) fixes, for the general ratio (z) of equation (1), a mid-way point between the activities (energy-fluxes) denoted by $\left(2 v_{0} \mathrm{~T}_{1}, \mathrm{~T}^{\prime \prime} v_{0} / \gamma\left(v_{0}\right)\right)$. But specializing $(z)$ into $\left(\gamma\left(v_{o}\right)\right)$ throws the assigned electromagnetic activity unsymmetrically into that interval. This outcome conforms reasonably with building on the basis afforded by the last member of equation (7). Provided that

$$
\left.\begin{array}{rl}
\frac{\mu_{2}{ }^{\prime} c^{2}}{z} \equiv \frac{2 \mathrm{E}}{z}-\frac{n \mathrm{E}}{z^{2}} ; \frac{d}{d t}\left[\frac{\mu_{2}{ }^{2} c^{2}}{z}+\frac{n \mathrm{E}}{z^{2}}\right] & =\frac{2}{z} \frac{d \mathrm{E}}{d t}-\frac{2 \mathrm{E}}{z^{2}} \frac{d z}{d t} \\
=2 v \mathrm{~T}_{1}-v^{2} \frac{d m^{\prime}}{d t} & =v^{\prime} \mathrm{T}_{1}+m^{\prime} v \frac{d v}{d t} ; \\
\frac{d}{d t}\left[\frac{\mu_{2}^{\prime} c^{2}}{z}+\frac{n \mathrm{E}}{z^{2}}\right]-\frac{3}{4} m^{\prime} v \frac{d v}{d t} \\
=v\left(\mathrm{~T}_{1}+\frac{m^{\prime}}{4} \frac{d v}{d t}\right) .
\end{array}\right]
$$

The preceding treatment of electromagnetic activity is in the first instance empirical, let it be granted. For one thing, it adheres to an activity-value whose exact validity is perhaps not yet beyond question. Supposing, however, this datum to remain unshaken under renewed critical examination, the foregoing. "cut-and-try" result can be rationalized, at least partially, by comparing it with the routine in terms of $\left(\mu^{\prime}, \mu\right)$ and of $\left(\mu_{1}^{\prime}, \mu_{1}\right)$. Let us lay out the main steps of that analysis, by way of conclusion. Consider first the activities for the speed $\left(v_{1}\right)$, based on equations $(1,38)$,

$v_{1} \frac{d}{d t}(c \mu)=c^{2} \frac{d \mu^{\prime}}{d t}-c \mu \frac{d v_{1}}{d t} ; v_{1} \frac{d}{d t}\left(c \mu_{1}\right)=c^{2} \frac{d \mu_{1}^{\prime}}{d t}-c \mu_{1} \frac{d v_{1}}{d t}$.

* Particularly (III.), eq. 29; and the routine of eq. $(11,12)$ there. 
For present conditions, on adding in the second case the " unconverted activity," $\left(2 v_{1} \mathrm{~T}_{1}\right)$ appears repartitioned thus :

Hence

$$
\left.\begin{array}{l}
\mathrm{A} \equiv v_{1} \frac{d}{d t}(c \mu)=2 v_{1} \mathrm{~T}_{1}-v_{1} \mathrm{~T}_{1} ; \\
\mathrm{A}_{1} \equiv v_{1} \frac{d}{d t}\left(c \mu_{1}\right)+m_{1} v \frac{d v}{d t}=2 v_{1} \mathrm{~T}_{1}-\frac{1}{2} v \mathrm{~T}^{\prime \prime} .
\end{array}\right\}
$$

$$
\left.\begin{array}{l}
\frac{\mathrm{A}-\mathrm{A}_{1}}{2}=-\frac{m^{\prime \prime}}{4} v \frac{d v}{d t} ; \\
\frac{\mathrm{A}+\mathrm{A}_{1}}{2}=v_{1} \mathrm{~T}_{1}+\frac{m{ }^{\prime \prime}}{4} v \frac{d v}{d t}=\frac{v^{\prime} \mathrm{I}^{\prime \prime}}{2}+\frac{3}{4} m^{\prime \prime} v \frac{d v}{d t}
\end{array}\right\} .
$$

This agrees with one particular (empirical) rearrangement of equation (9), after reducing the working-speed to $(v)$; exploiting the flexibility of a zero-difference :

$$
\left[2 v \mathrm{~T}_{1}-\frac{v}{2} \frac{\mathrm{T}^{\prime \prime}}{\gamma(v)}-\frac{m^{\prime}}{4} v \frac{d v}{d t}\right]-\left[\frac{v}{2} \frac{\mathrm{T}^{\prime \prime}}{\gamma(v)}+\frac{3}{4} m^{\prime} v \frac{d v}{d t}\right]=0
$$

And the magnitude of the last item coincides with the time-rate of the corresponding electromagnetic potential. The quoted value of electromagnetic energy-flux rejects, we might say, both extreme suppositions, of $\left(A, A_{1}\right)$; it is determined symmetrically between them. How far does this support the assertion of mass in the Lorentz electron?

Proper candour can admit this whole system of equations to be finally inconclusive, and yet hold to their present usefulness. So long as aggregates only are accessible, the search for their physical constituents will grope more or less blindly. The close of that period will be hastened by first enlarging the list of possibilities, and at last weighing them impartially. The simple thoughts of this paper do no more than exemplify a method, it is true, without exhibiting it in formal terms or delimiting it. But it can scarcely be doubtful that such a widening of Lagrange's plan is of good promise for the further discussion of energy-fluxes in terms of mechanics.

University of California. 